\section{Ueber eine eigenartige Form von Ostitis bei Kriegsteilnehmern.}

Von Oberstabsarzt Carl Franz

(o. Prof. der Kriegschirurgie an der Kaiser Wilhelm-Akademie zu Berlin) z. Z. Beratender Chirurg.

Kraus und Citron beschreiben in Nr. 28 dieser Wochenschrift eine Form von Ostitis der Tibien, deren Aetiologie dunkel sei und die nach ihrer Ansicht etwas "Eigenartiges" habe. Der Schlußsatz des Artikels, ,gegenteiliger Belehrung sind wir natürlich nicht unzugänglich", legt es mir nahe, mich über diese Erkrankung auszulassen.

Wenn es auch immer etwas Mißliches an sich hat, sich über Krankheitsfälle zu äußern, deren Träger man nicht persönlich untersucht hat, so ist doch die Beschreibung des Krankheitsbildes so vorzüglich, daß es für mich keinem Zweifel unterliegt, daß wir es hier mit derjenigen Krankheit zu tun haben, die der Mehrzahl der Militärärzte, insbesondere aber den Militärchirurgen ganz geläufig ist und die, wie ich schon früher im Frieden oft festzustellen Gelegenheit hatte, den Zivilärzten etwas Unbekanntes war. Es handelt sich um eine traumatische Periostitis der Schienbeine. Sie wird bedingt durch Zerrungen am Periost der Tibia infolge einmaliger, meistens aber wiederholter übergroßer Inanspruchnahme der tiefen, an der Innen- und Rückseite der Tibia ansetzenden Wadenmuskulatur oder - das ist aber viel seltener der Fall - der an der Außenseite ansetzenden Streckmuskulatur. Man sieht sie namentlich in der Rekrutenausbildungsperiode dann, wenn langsamer Schritt und Parademarsch geübt wird, oder bei Reservisten, die zu Uebungen eingezogen werden. Die Herren Kra us und Citron beschreiben sehr schön den O-Beingang dieser Patienten, d. h. das Auftreten mit der Außenkante des Fußes. Er ist natürlich, denn die Kranken vermeiden instinktiv die Benutzung der tiefen Fußbeuger, weil dadurch Zerrungen am Periost der Tibia und neue Schmerzen hervorgerufen werden. Die Oedcme sitzen vorwiegend in den mittleren zwei Vierteln der Tibien, doch kann im Anfang die ganze Schienbeinfläche bis zur Tuberositas von einer Schwellung umgeben sein. Jedenfalls findet man fast immer, wenn die Erscheinungen abklingen, da $B$ die schmerzhaften, oft sehr harten Schwellungen an der Innenkante in obengenanntem Bezirk sitzen und sehr lange zurückbleiben. Läßt man die Soldaten zu früh aufstehen, so treten sofort wiederleichte oder schwèrere ödematöse Schwellungen größerer Schienbeingebiete auf. Ergänzen möchte ich das von den beiden Herren gekennzeichnete Bild noch dadurch, daß es auch Fälle gibt, bei denen das Oedem anfangs mit leichten Entzündungserscheinungen der Haut einhergeht. Das Röntgenbild ergibt uns in diesen Fällen leichtes Verschwommensein der Umrisse. Temperatursteigerungen sind anfangs sehr häufig vorhanden. Sonstige Allgemeinerscheinungen, wie Kopfschmerzen und Schwindel, wie sie im Fall 3 von den Autoren beschrieben sind, halte ich für eine zufällige Komplikation. Zum Wesen der Erkrankung gehören sie nach unseren hundertfachen Erfahrungen nicht.

Diese traumatische, durch fortdauernde mechanische Insulte bedingte Periostitis der Tibien ist eine langwierige Erkrankung und nicht nur für den Träger, sondern auch für die zuständigen Kompagniechefs und Aerzte ein Kreuz, weil sie lange Zeit rückfällig bleibt und die volle dienstliche Inanspruchnahme der betreffenden Soldaten verhindert. Die beste Behandlung besteht nach meiner Erfahrung in einem fixierenden
Verband bei rechtwinkliger Stellung des Fußgelenks, eventuell in Kombination mit Heißluftbädern. Die mittleren Grade haben immerhin vier bis sechs Wochen Dauer, und es ist unbedingt notwendig, diese Patienten allmählich systematisch an den ausgiebigen Gebrauch ihrer tiefen Wadenmuskulatur zu gewöhnen. Solange nach Exerzieren mit Parademarsch und wiederholtem ,Fersen hebt" noch Oedeme am Abend auftreten, sind die Leute nicht vollkommen felddienstfähig, während Verdickungen der Tibia auch dann, wenn sie auf Druck noch schmerzhaft sind, kein Hindernisgrund sind. Erfahrungsgemäß sind durchschnittlich drei Monate notwendig, bis die Kranken dem vollen Dienst wiedergegeben werden können.

Hinweisen will ich noch auf einen oft erhobenen Einwand, $\mathrm{da} ß$ diese Periostitis nicht auf eine zu große Inanspruchnahme der Beinmuskulatur zurückgeführt werden dürfe, weil die Erkrankten aus einem körperlich schwer arbeitenden Berufe stammten oder doch schon längere Zeit im Felde gestanden haben. Der Einwand ist hinfällig, denn kein Beruf erfordert eine so starke Inanspruchnahme aller Beinmuskeln, wie der des Infanteristen, und zweitens muß der Soldat gerade im Felde häufig mit einem seinem Fuß nicht angepaßten Schuhwerk laufen oder stehen, das unverhältnismäßige Anspannungen bestimmter Muskelgruppen bedingt.

K. H.-Q., den 27. Juli 1916. 